\title{
Genetic Variability of Agronomic Traits as Potential Indicators of Drought Tolerance in Common Beans (Phaseolus vulgaris $\mathrm{L}_{\text {.) }}$
}

\author{
Charles Langat $\mathbb{D}^{1},{ }^{1}$ Omwoyo Ombori, ${ }^{2}$ Philip Leley, ${ }^{1}$ David Karanja, ${ }^{1}$ Richard Cheruiyot, ${ }^{2}$ \\ Moses Gathaara, ${ }^{2}$ and Benard Masila (iD) \\ ${ }^{1}$ Kenya Agricultural and Livestock Research Organization (KALRO), Machakos, Kenya \\ ${ }^{2}$ Department of Plant Science, Kenyatta University, Kahawa, Kenya \\ Correspondence should be addressed to Charles Langat; charlestlangat@gmail.com
}

Received 3 April 2019; Accepted 3 July 2019; Published 25 August 2019

Academic Editor: Isabel Marques

Copyright ( 92019 Charles Langat et al. This is an open access article distributed under the Creative Commons Attribution License, which permits unrestricted use, distribution, and reproduction in any medium, provided the original work is properly cited.

\begin{abstract}
Sixteen progeny lines of common beans obtained from single crosses made between two parents, GLP2 and KAT B1, were grown in randomized complete block design in a rainout shelter at the Agricultural and Mechanization Research Institute, Machakos, Kenya. The experiment was conducted to study inheritance of traits associated with drought stress adaptation and to establish if significant variation for those traits was existing in order to carry out selection for drought tolerance. The calculated mean values were used to estimate heritability, genetic advance, and correlation study for each trait. Water stress had a significant $(p \leq 0.01)$ effect on the number of pods per plant, grains per plant, 100-seed weight, and yield per plant. The highest values for genotypic coefficient of variation $(36.11 \%)$ and phenotypic coefficient of variation $(36.70 \%)$ were recorded for pods plant ${ }^{-1}$ under stress $^{-1}$ condition. Highest broad-sense heritability estimates (96.54\%, 94.97\%, and 93.16\%) coupled with high genetic advance as percent of the mean $(22.32 \%, 34.97 \%$, and $26.32 \%)$ were obtained for the number of pods plant ${ }^{-1}$, days to maturity, and yield plant ${ }^{-1}$, respectively, showing that selection of these traits together could lead to yield improvement under stressed conditions. Harvest index showed a significant and positive relationship with biomass aboveground $(r=0.86)$ and the number of pods plant ${ }^{-1}$ $(r=0.86)$ indicating the possibility of identifying high performing lines of common beans for drought stress environment for further studies on these traits.
\end{abstract}

\section{Introduction}

Common bean is the single most significant source of dietary protein for majority of households in Kenya. However, the annual demand for this commodity far outstrips its availability. The shortage is especially occasioned by low productivity due to genotypes with low yield potential and unfavorable growing conditions due to low and poorly distributed rainfall [1]. Hence, there is a great need to identify elite genotypes with higher yield and drought tolerance traits for cultivation in water stress areas or to be used as parent in hybridizing/breeding programme. The success of selecting genotypes with high potential in plant breeding program depends on the extent and nature of phenotypic and genotypic variability in several agronomic traits of the population. The prerequisite for coming up with a reliable breeding programme for improvement of a specific attribute in any crop could be a study on the genetic parameters, viz., variation, inheritance, and genetic advance [2]. Coefficients of variation are very helpful in the estimation of the magnitude of variability which is present within a population. On the contrary, the estimates of heritability not only offer an indication of the degree of transmissibility of a particular trait but also show the effectiveness of selection. Further, to find the expected genetic gain in a next generation, heritability estimates have to be considered along the genetic advance values $[3,4]$. Generally, traits that display high genetic advance alongside high values of heritability could possibly suggest that when selected together they may lead to improved yield under a given drought stress. Similarly, low estimates for the coefficient of variation suggest lack of genetic variation among the traits in question while high 
values of coefficient of variation indicates that selection is effective for that particular trait because of the wider genetic variability.

According to Alvares et al. [5], understanding the magnitude of genetic variation present within a population of common bean as well as adequate characterization of useful physiological traits and their association with yield and yield components would be extremely necessary for plant breeders working to improve the drought tolerance ability of the crop. However, limited information is available on the genetic variability of some phenological and physiological traits expressed under drought stress and on inheritance of yield and related yield component traits among the local genotypes of common beans in Kenya [6]. Therefore, this study was carried out to measure the variability of physiological traits with the yield component traits under water stress and wellwatered environments. This estimate was aimed at heritability and gain from selecting eleven traits in F2 populations and assessing the likelihood of using them in selection for tolerance to drought in common bean.

\section{Materials and Methods}

An intraspecific cross between two common bean genotypes, GLP2 and KAT B1, was carried out to develop F2 progenies. The two genotypes have contrasting drought tolerance characteristics; GLP2 is drought susceptible while KAT B1 is drought tolerant based on their productivity under drought stress conditions. A total of 16 F2 progenies that were developed through the single seed descent method were evaluated for phenological, physiological, yield and yieldrelated components traits, and drought tolerance along with parental genotypes during 2017/2018 in a rainout shelter at the Agricultural and Mechanization Research Institute, Katumani, Kenya.

2.1. Experimental Design. The experimental materials comprising sixteen progenies and two parental lines were sown in plastic pots and arranged in a randomized complete block design (RCBD) with four replications. A total of 72 pots were used each measuring $22 \mathrm{~cm}$ high and $20 \mathrm{~cm}$ in diameter, and they were filled with Lixisol soils (textural class of loams $50.3 \%$, silt $26.4 \%$, and $23.3 \%$ sand). Five seeds were sown per pot, and two weeks after sowing, seedlings were thinned to three. Irrigation was done daily for a period of three weeks. A week after establishment, half of the plants were subjected to stress continuously until physiological maturity, whereas others were well watered (control). Water levels were maintained at a field capacity of $75 \%$ in the wellwatered treatment while the stress treatment was kept at the range of $30 \%$ of field capacity. Artificial water deficit was created through withholding irrigation. This was done to simulate the water stress conditions experienced by the plant in the field. Hand weeding was carried out occasionally to ensure the crops were healthy.

2.2. Data Collection. For plant characters, data were recorded on five random plants in each replication at the end of flowering season. Ten days after withholding water, data sampling for plant traits was done between 10.30 and 11.30 a.m. using three randomly selected plants of each line per plot in the four replications. The characters measured include days to flowering, days to maturity, number of branches per plant, number of pods per plant, number of grains per pod, 100-seed weight, harvest index, stomatal conductance, water use efficiency, and leaf water potential.

\subsection{Measurement of Yield and Yield-Related Component} Traits. The performance of genotypes under drought is determined by the grain yield and yield-related components under drought. At the midpod filling stage, the number of branches and number of pods per plant were counted and recorded from each of the randomly selected plants per plot. At physiological maturity, the plants from each pot were cut individually at the base and placed in separate bags. Samples in each bag were partitioned into stem, leaves, grains, and pods and packed separately. Measurements for each component was made and recorded. With the exception of the seeds, all the other plant components were oven-dried at $85^{\circ} \mathrm{C}$ for 72 hours and pod weight, stem weight, and leaf weight were determined. The measurements were subsequently used for analysis for yield and associated traits, viz., aboveground biomass, number of grains per plant, grain yield, 100-grain weight, and harvest index.

2.4. Measurements of Phenological Traits. Days to flowering (DF) was estimated as the number of days between the date of sowing until when $50 \%$ of the plants in the plot had one fully open flower, whereas days to physiological maturity (DPM) was defined as the number of days between the date of sowing and when $50 \%$ of the pods had lost their green colour.

2.5. Measurements of Physiological Traits. Measurements for stomatal conductance were carried out on both surfaces of the fully expanded uppermost leaf of three plants per plot using a LI1600 steady state porometer (LICOR, Lincoln, NE). Sampling was done on the $14^{\text {th }}, 21^{\text {st }}, 28^{\text {th }}$, and $35^{\text {th }}$ day after emergence. To determine leaf water potential, leaf samples were taken from each plot in the four replicates of both treatments $14^{\text {th }}, 21^{\text {st }}, 28^{\text {th }}$, and $35^{\text {th }}$ day after emergence.

2.6. Statistical Analysis. Data obtained for the different characters in both individual and combined moisture treatments were analyzed using analysis of variance (ANOVA) with SAS software version 9.1.3. A combined analysis was performed assuming a random model for treatment and genotypes [7]. Estimation of genetic parameters and correlation was done as per the procedures described by Robinson et al. [8], Burton and Devane [9], Hanson et al. [10], and Gomez and Gomez [11]. 
The genotypic and phenotypic components of variance for the traits were calculated according to a formula by Burton and Devane [9], as follows:

$$
\text { genetic variance }\left(\sigma_{\mathrm{g}}^{2}\right)=\frac{\text { (genotype mean square }(\mathrm{GMS})-\text { error mean square }(\mathrm{EMS}))}{(\text { number of replications }(r))} \text {, }
$$

environmental variance $\left(\sigma_{\mathrm{e}}^{2}\right)=$ error mean square,

$$
\text { phenotypic variance }\left(\sigma_{\mathrm{p}}^{2}\right)=\sigma_{\mathrm{g}}^{2}+\sigma_{\mathrm{e}}^{2} \text {. }
$$

The genotypic, phenotypic, and environmental variances were used for the estimation of phenotypic and genotypic coefficient of variation as suggested by Burton and Devane [9], as follows:

$$
\begin{aligned}
& \text { PCV } \%=\frac{\sqrt{\sigma_{\mathrm{p}}^{2}}}{x} \times 100, \\
& \mathrm{ECV} \%=\frac{\sqrt{\sigma_{\mathrm{e}}^{2}}}{x} \times 100, \\
& \mathrm{GCV} \%=\frac{\sqrt{\sigma_{\mathrm{g}}^{2}}}{x} \times 100,
\end{aligned}
$$

where PCV\% = phenotypic coefficient of variability, GCV\%= genotypic coefficient of variability, $\mathrm{ECV} \%=$ environmental coefficient of variability, $\sigma_{\mathrm{p}}^{2}=$ phenotypic variance, $\sigma_{\mathrm{g}}^{2}=$ genetic variance, $\sigma_{\mathrm{e}}^{2}=$ environmental variance, and $x=$ grand mean.

The GCV and PCV values were classified as low, moderate, and high according to Robinson et al. [8] as follows: low $=<10 \%$, moderate $=10-20 \%$, and high $=>20 \%$.

Broad-sense heritability was calculated according to the method in [10]:

$$
h_{\mathrm{B}}^{2}=\frac{\sigma_{\mathrm{g}}^{2}}{\sigma_{\mathrm{p}}^{2}} \times 100
$$

where $h_{\mathrm{B}}^{2}=$ heritability in broad sense, $\sigma_{\mathrm{g}}^{2}=$ genetic variance, and $\sigma_{\mathrm{p}}^{2}=$ phenotypic variance.

The heritability values were ranked according to Robinson et al. [8] as follows: low $=<30 \%$, moderate $=30-60 \%$, and high $=>60 \%$.

The expected genetic advance or gain (GA) of selection for the trait was computed as

$$
\mathrm{GA}=K \sqrt{\sigma_{\mathrm{P}}^{2} h_{\mathrm{B}}^{2}}
$$

where $K=1.40$ intensity of selection at $5 \%, \sigma_{\mathrm{p}}^{2}=$ phenotypic variance, and $h_{\mathrm{B}}^{2}=$ heritability in broad sense.

The genetic advance is given as percentage of the mean:

$$
\mathrm{GAM}=\frac{\mathrm{GA}}{x} \times 100
$$

where $\mathrm{GA}=$ genetic advance and $x=$ grand mean.

The GAM were classified as low, moderate, and high according to Robinson et al. [8] as follows: low $=<10 \%$, moderate $=10-20 \%$, and high $=>20 \%$.

\section{Results}

3.1. Variation in Traits of the Common Bean Population. Table 1 shows the mean squares and coefficients of variation (CV) for 16 progenies of common bean. Response to water stress treatment was highly significant $(p \leq 0.01)$ for pods per plant, grain per plant, yield per plant, and 100-seed weight while significant differences $(p \leq 0.05)$ were observed under stress and nonstress conditions for all the other traits ( $\mathrm{Ta}-$ ble 1). There was considerable variability among the various traits within population under consideration (Table 1). The highest population diversity was recorded under stress conditions in the biomass aboveground (38.06\%), followed by the number of branches plant ${ }^{-1}(28.03 \%)$, the number of pods plant ${ }^{-1}(26.95 \%)$, harvest index $(24.80 \%)$, the number of grains $\operatorname{pod}^{-1}(21.85 \%)$, and stomatal conductance $(21.02 \%)$. There was moderate diversity in the number of branches plant ${ }^{-1}(18.03 \%)$ and yield plant ${ }^{-1}(16.86 \%)$ under the stressed environment. Under the well-watered environment, there was moderate diversity on days to maturity (12.37\%), number of branches plant ${ }^{-1}(10.02 \%)$, number of pods plant ${ }^{-1},(10.37 \%)$, stomatal conductance $(13.29 \%)$, leaf water potential $(10.51 \%)$, 100 -seed weight $(14.54 \%)$, and number of grains pod $^{-1}(11.40 \%)$. The lowest population diversity was found under stressed conditions for days to flowering $(5.83 \%)$, days to maturity $(3.70 \%)$, and 100 -seed weight.

3.2. Variance of Components $\left(\sigma^{2}\right)$. Variance of components estimations revealed that environmental variance strongly influenced most of the traits of common population ( $\mathrm{Ta}$ ble 2). There were small differences between phenotypic and genotypic variance for almost all traits. The genotypic variance ranged from 0.05 (leaf water potential) to 21.26 (number of pods plant ${ }^{-1}$ ). Result showed that the highest shared genetic variance component was found to be the number of pods plant ${ }^{-1}$ (21.26) and yield plant ${ }^{-1}$ (14.85) under stress environment while number of hundred seed weight (13.01) was recorded under watered conditions. Stomatal conductance (8.76), days to maturity (7.55), and 
TABLE 1: Analysis of variance for eleven traits of common bean population.

\begin{tabular}{|c|c|c|c|c|c|}
\hline Trait & Level & $\begin{array}{l}\text { Replication mean squares } \\
\text { (RMS) }\end{array}$ & $\begin{array}{l}\text { Population mean squares } \\
\text { (PMS) }\end{array}$ & $\begin{array}{c}\text { Error mean squares } \\
(\text { EMS })\end{array}$ & $\begin{array}{c}\text { Coefficient of } \\
\text { variation } \\
(\mathrm{CV} \%)\end{array}$ \\
\hline \multirow{2}{*}{ DF } & Watered & 7.59 & $12.81^{*}$ & 0.42 & 7.75 \\
\hline & Stressed & 4.56 & $9.1^{*}$ & 0.29 & 5.83 \\
\hline \multirow{2}{*}{$\mathrm{DM}$} & Watered & 70.7 & $2.3^{*}$ & 0.40 & 5.43 \\
\hline & Stressed & 17.4 & $28.6^{*}$ & 0.40 & 3.70 \\
\hline \multirow{2}{*}{$\mathrm{BP}$} & Watered & 2.76 & $2.59^{*}$ & 0.35 & 12.37 \\
\hline & Stressed & 0.44 & $8.58^{*}$ & 0.60 & 28.03 \\
\hline \multirow{2}{*}{$\mathrm{PP}$} & Watered & 12.91 & $8.1^{*}$ & 0.70 & 10.02 \\
\hline & Stressed & 0.33 & $85.8^{* *}$ & 0.76 & 26.95 \\
\hline \multirow{2}{*}{ STML } & Watered & 3.11 & $32.7^{*}$ & 0.48 & 13.29 \\
\hline & Stressed & 0.29 & $46.37^{*}$ & 0.25 & 21.02 \\
\hline \multirow{2}{*}{ LWP } & Watered & 10.93 & $1.72^{*}$ & 1.03 & 6.51 \\
\hline & Stressed & 2.78 & $33.47^{*}$ & 0.15 & 10.51 \\
\hline \multirow{2}{*}{ HSW } & Watered & 7.68 & $8.43^{*}$ & 6.41 & 10.79 \\
\hline & Stressed & 0.14 & $4.17^{* *}$ & 0.34 & 9.77 \\
\hline \multirow{2}{*}{ BG } & Watered & 0.47 & $1.21^{*}$ & 0.29 & 14.54 \\
\hline & Stressed & 0.92 & $9.99^{*}$ & 1.19 & 38.06 \\
\hline \multirow{2}{*}{ GP } & Watered & 0.18 & $0.38^{*}$ & 0.09 & 5.71 \\
\hline & Stressed & 0.53 & $12.25^{* *}$ & 0.33 & 21.85 \\
\hline \multirow{2}{*}{ YP } & Watered & 0.023 & $0.2^{*}$ & 0.08 & 11.40 \\
\hline & Stressed & 2.89 & $60.48^{* *}$ & 1.09 & 16.86 \\
\hline \multirow{2}{*}{ HI } & Watered & 0.075 & $0.14^{*}$ & 0.09 & 7.53 \\
\hline & Stressed & 1.07 & $23.49^{*}$ & 1.77 & 24.80 \\
\hline
\end{tabular}

${ }^{*, * *}$ Significant at $5 \%$ and $1 \%$ probability levels, respectively. DF: days to flowering; DM: days to maturity; BP: number of branches/plant; PP: number of pod/ plant; STMLC: stomatal conductance; LWP: leaf water potential; HSW: 100-seed weight; BG: biomass aboveground; GP: number of grain/pod; YP: yield/ plant; HI harvest index.

TABLE 2: Estimates of phenotypic and genetic parameters for the studied traits.

\begin{tabular}{|c|c|c|c|c|c|c|c|c|c|}
\hline Traits & Level & $\sigma_{\mathrm{g}}^{2}$ & $\sigma_{\mathrm{e}}^{2}$ & $\sigma_{\mathrm{p}}^{2}$ & GCV\% & PCV\% & $h^{2} \%$ & GA & GAM $\%$ \\
\hline \multirow{2}{*}{ DF } & Watered & 3.10 & 0.42 & 3.52 & 17.61 & 19.20 & 88.07 & 2.46 & 22.41 \\
\hline & Stressed & 2.45 & 0.29 & 2.74 & 15.65 & 11.23 & 89.42 & 2.19 & 19.92 \\
\hline \multirow{2}{*}{ DM } & Watered & 2.03 & 0.4 & 2.43 & 14.25 & 15.63 & 83.54 & 1.99 & 18.13 \\
\hline & Stressed & 7.55 & 0.4 & 7.95 & 27.48 & 25.58 & 94.97 & 3.85 & 34.97 \\
\hline \multirow{2}{*}{$\mathrm{BP}$} & Watered & 0.56 & 0.35 & 0.91 & 1.48 & 1.52 & 61.5 & 1.05 & 9.52 \\
\hline & Stressed & 2.00 & 0.60 & 2.60 & 14.14 & 14.33 & 79.92 & 2.02 & 18.35 \\
\hline \multirow{2}{*}{ PP } & Watered & 9.60 & 0.70 & 10.30 & 30.98 & 27.17 & 73.20 & 4.34 & 32.16 \\
\hline & Stressed & 21.26 & 0.76 & 22.02 & 36.11 & 36.70 & 96.54 & 6.45 & 22.32 \\
\hline \multirow{2}{*}{ STMLC } & Watered & 3.02 & 0.61 & 3.44 & 20.45 & 21.89 & 77.65 & 1.85 & 17.28 \\
\hline & Stressed & 8.76 & 0.6 & 9.03 & 36.13 & 33.47 & 84.25 & 2.06 & 19.87 \\
\hline \multirow{2}{*}{ LWP } & Watered & 0.05 & 0.09 & 0.17 & 2.37 & 2.28 & 43.40 & 0.29 & 2.86 \\
\hline & Stressed & 2.73 & 0.21 & 2.29 & 16.80 & 14.37 & 60.14 & 4.27 & 25.46 \\
\hline \multirow{2}{*}{ HW } & Watered & 13.01 & 6.41 & 19.42 & 36.07 & 32.37 & 66.99 & 5.05 & 27.72 \\
\hline & Stressed & 0.96 & 0.34 & 1.30 & 2.80 & 2.17 & 73.85 & 1.37 & 12.47 \\
\hline \multirow{2}{*}{ BG } & Stressed & 0.96 & 0.34 & 1.30 & 2.80 & 2.17 & 73.85 & 1.37 & 12.47 \\
\hline & Watered & 0.23 & 0.29 & 0.52 & 1.80 & 0.87 & 44.23 & 0.67 & 6.10 \\
\hline \multirow{2}{*}{ GP } & Stressed & 2.20 & 1.19 & 3.39 & 4.83 & 5.65 & 64.90 & 2.08 & 28.88 \\
\hline & Watered & 0.07 & 0.09 & 0.16 & 2.65 & 2.27 & 43.75 & 0.37 & 3.37 \\
\hline \multirow{2}{*}{ YP } & Stressed & 2.98 & 0.33 & 3.31 & 17.26 & 15.52 & 90.03 & 2.42 & 21.97 \\
\hline & Watered & 0.03 & 0.08 & 0.11 & 1.73 & 1.18 & 67.27 & 0.24 & 2.20 \\
\hline \multirow{2}{*}{$\mathrm{HI}$} & Stressed & 14.85 & 1.09 & 15.94 & 28.54 & 26.57 & 93.16 & 5.39 & 26.32 \\
\hline & Watered & 0.09 & 0.09 & 0.04 & 1.00 & 2.01 & 50.00 & 0.06 & 5.57 \\
\hline
\end{tabular}

$\overline{\sigma_{g}^{2}}$ : genotypic variance; $\sigma_{\mathrm{e}}^{2}$ : environmental variance; $\sigma_{\mathrm{p}}^{2}$ : phenotypic variance; GCV: genotypic coefficient of variation; PCV: phenotypic coefficient of variation; $h^{2}$ : heritability; GA: genetic advance; GA\%: genetic advance as percentage of mean; DF: days to flowering; DM: days to maturity; NBP: number of branches/plant; NPP: number of pod/plant; STMLC: stomatal conductance; LWP: leaf water potential; HSW: 100-seed weight; BAG: biomass aboveground; NGP: number of grain/pod; YP: yield/plant; HI: harvest index. 
harvest index (5.43) exhibited a moderate genotypic variance under stress conditions, whereas the rest of the parameters exhibited low estimates of genotypic variance under stress environment and well-watered environment (Table 2). High phenotypic variance was observed for the number of pods plant $^{-1}$ (22.02) and yield plant ${ }^{-1}$ (15.94 gm) under stress environment and harvest index (19.42) and the number of pods plant $^{-1}$ (10.30) under watered environment. Moderate phenotypic variance was recorded for days to maturity (7.95), stomatal conductance (9.03), and harvest index (7.20) under stress environment, and low phenotypic variance was reported for the rest of the traits.

\subsection{Phenotypic and Genotypic Coefficients of Variation.} There was a relatively large coefficient of variability among the genotypes with regards to all the studied traits that were considered (Table 2). The genotypic coefficient of variation (GCV) ranged from $1.48 \%$ to $36.11 \%$, while the phenotypic coefficient of the variation (PCV) ranged from $1.18 \%$ for yield plant ${ }^{-1}$ to $36.70 \%$ for the number of pods plant $^{-1}$. Traits that showed high genotypic coefficient of variation were the number of pods plant ${ }^{-1}(36.11 \%)$ followed by hundred seed weight (36.07\%), stomatal conductance $(30.13 \%)$, yield plant ${ }^{-1}(28.54 \%)$, and days to maturity $(27.48 \%)$. There was a low genotypic coefficient of variation on the number of branches plant ${ }^{-1}(1.48 \%)$, while there was a moderate genotypic coefficient of variation on the number of days to flowering (17.61\%), leaf water potential $(16.80 \%)$, grains $\operatorname{pod}^{-1}(17.26 \%)$, and harvest index $(13.30 \%)$. The phenotypic coefficient of variation was high on the number of pods plant ${ }^{-1}$ (36.70\%) followed by stomatal conductance $(33.47 \%)$, hundred seed weight $(32.37 \%)$, yield plant ${ }^{-1}(26.57 \%)$, and days to maturity (25.58\%), whereas low phenotypic coefficient of variation was recorded for branches plant ${ }^{-1}$ $(1.18 \%)$ but moderate phenotypic coefficient of variation was noticed for days to flowering (19.20\%), days to maturity (15.63\%), branches plant ${ }^{-1}(14.33 \%)$, leaf water potential $(14.37 \%)$, grains plant ${ }^{-1}(15.52 \%)$, and harvest index $(12.00 \%)$.

3.4. Heritability $\left(h^{2}\right)$. The estimates of heritability obtained from the study varied between $43.40 \%$ and $96.54 \%$ (Table 2). The lowest value was recorded for leaf water potential (43.40\%) under the well-watered environment. Similarly, the moderate values for biomass aboveground (43.75\%), yield per plant $(44.23 \%)$, and 100 -seed weight $(50 \mathrm{gm})$ were all obtained from the well-watered environment. The rest of the traits had high values $(<60 \%)$ from both well-watered and stressed conditions.

3.5. Expected Genetic Advance (GAM\%). The genetic advance (GA) estimates for eleven traits of the common bean population studied are shown in (Table 2). In this study, high GAM were recorded on days to maturity $(34.97 \%)$, harvest index $(29.66 \%)$, yield per plant $(26.32 \%)$, number of pods per plant $(22.32 \%)$, and number of grains per pod
(21.97\%) under stress condition (Table 2). High GAM were recorded on the number of branches per plant $(32.16 \%)$, number of pods per plant $(27.72 \%)$, and days to flowering $(22.41 \%)$ were recorded under watered conditions. Moderate GAM were recorded for days to flowering (19.92\%), stomatal conductance $(19.87 \%)$, biomass aboveground (18.88\%), number of branches per plant (18.35), and 100seed weight $(12.47 \mathrm{gm})$ under stress environment while under watered condition, days to maturity (18.35\%) recorded moderate GAM (Table 2). Days to maturity (9.52\%), 100-seed weight (6.10\%), yield per plant $(5.57 \%)$, biomass aboveground (3.37\%), and number of grains per pod $(2.20 \%)$ were obtained for low genetic advance as percent of the mean.

3.6. Pearson Correlation Analysis among Eleven Traits of the Sixteen F2 Progenies and Two Parents. The highest values of correlations were between yield per plant with DF $(r=0.86), \mathrm{HI}(r=0.79), \mathrm{GP}(r=0.80), \mathrm{BG}(r=0.86), \mathrm{HSW}$ $(r=0.85)$, and PP $(r=0.86)$. This relationship was particularly obtained under stressed condition (Table 3 ). However, weak correlations were observed between yield per plant with DF $(r=-0.41)$ and DM $(r=-0.23)$ under well-watered condition. Though components such as number of grain per pod and yield per plant showed very strong positive association $(r=0.80)$ with each other, they exhibited a negative and low correlations with DF $(r=-0.41),(r=-0.26)$ and DM $(r=-0.28, r=-0.34)$, respectively, under watered treatments. Days to flowering exhibited a positive and significant correlation with DM $(r=0.54)$, SMTL $(r=0.57)$, BP $(r=0.62)$, PP $(r=0.68)$, and HSW $(r=0.55)$ under stressed environment, but under well-watered condition, the only significant positive correlation was on the number of branches while others were negative, but not always significant. The correlation of days to flowering with the number of pods per plant, number of branches per plant, and days to maturity was each noted to be negatively nonsignificant DF $(r=-0.33)$, PP $(r=-0.44)$, BP $(r=-0.39)$, and DM $(r=-0.23)$ with yield per plant under watered conditions.

Day to maturity exhibited a generally negative and low correlation with BP $(r=-0.43)$, STML $(r=-0.20)$, LWP $(r=-0.43)$, PP $(r=-0.21)$, HSW $(r=-0.18)$, and BG $(r=-0.23)$ under watered conditions, whereas the results for the stressed environment were significant but was low for BP $(r=0.57)$, STML $(r=0.49)$, LWP $(r=0.32)$, PP $(r=0.63)$, HSW $(r=0.58)$, and BG $(r=0.66)$. In addition, there were noticeable negative and low correlations between days to flowering and number of grains per pod under well-watered treatments $(r=-0.41)$, but the association between the two parameters was positive and strongly significant $(r=0.86)$ under stressed conditions. The correlation between number of branches per plant and number of pods per plant content was generally positive $(r=0.14)$ but low in stressed condition. There was a negative correlation between the number of branches per plant and biomass aboveground under watered condition. Positively strong and significant associations $(p \leq 0.10)$ 
TABle 3: Phenotypic correlations among different traits measured on progenies as result of crosses between GLP2 and KAT B1 under drought stress and nonstress.

\begin{tabular}{|c|c|c|c|c|c|c|c|c|c|c|c|c|}
\hline & & $\mathrm{DF}$ & $\mathrm{DM}$ & BP & $\mathrm{PP}$ & STML & LWP & HSW & BG & GP & $\mathrm{HI}$ & YP \\
\hline \multirow{2}{*}{ DF } & $\mathrm{a}$ & 1 & -0.41 & -0.30 & $-0.56^{*}$ & -0.21 & 0.33 & -0.29 & $0.58^{*}$ & -0.41 & -0.26 & -0.41 \\
\hline & $\mathrm{b}$ & 1 & $0.54^{*}$ & $0.62^{* *}$ & $0.68^{* *}$ & $0.57^{*}$ & 0.41 & $0.55^{*}$ & -0.15 & $0.69^{* *}$ & $0.58^{* *}$ & $0.86^{* *}$ \\
\hline \multirow{2}{*}{$\mathrm{DM}$} & $\mathrm{a}$ & & & -0.43 & -0.21 & -0.20 & -0.43 & -0.18 & -0.23 & -0.28 & -0.34 & -0.23 \\
\hline & $\mathrm{b}$ & & & $0.57^{*}$ & $0.63^{* *}$ & 0.49 & 0.32 & $0.58^{*}$ & $0.66^{* *}$ & $0.73^{* *}$ & $0.55^{*}$ & -0.41 \\
\hline \multirow{2}{*}{$\mathrm{BP}$} & $\mathrm{a}$ & & & & -0.40 & 0.28 & 0.17 & -0.24 & -0.32 & -0.17 & -0.21 & -0.39 \\
\hline & $\mathrm{b}$ & & & & 0.14 & 0.45 & 0.37 & $0.67^{* *}$ & $0.65^{* *}$ & $0.77^{* *}$ & $0.72^{* *}$ & 0.67 \\
\hline \multirow{2}{*}{$\mathrm{PP}$} & $\mathrm{a}$ & & & & & $0.53^{*}$ & 0.40 & -0.36 & -0.34 & 0.38 & -0.44 & $0.59^{*}$ \\
\hline & b & & & & & $0.69^{*}$ & $0.55^{*}$ & $0.59^{* *}$ & 0.47 & $0.69^{* *}$ & $0.71^{* *}$ & $0.86^{* *}$ \\
\hline \multirow{2}{*}{ STML } & $\mathrm{a}$ & & & & & & 0.33 & 0.45 & 0.44 & $0.58^{*}$ & 0.46 & 0.38 \\
\hline & $\mathrm{b}$ & & & & & & $0.78^{*}$ & $0.50^{*}$ & $0.53^{*}$ & $0.64^{*}$ & $0.51^{* *}$ & $0.73^{*}$ \\
\hline \multirow{2}{*}{ LWP } & $\mathrm{a}$ & & & & & & & -0.23 & $0.59^{*}$ & $0.63^{*}$ & $0.50^{*}$ & 0.41 \\
\hline & $\mathrm{b}$ & & & & & & & -0.28 & $0.66^{* *}$ & $0.70^{*}$ & $0.62^{*}$ & $0.68^{*}$ \\
\hline \multirow{2}{*}{ HSW } & $\mathrm{a}$ & & & & & & & & $0.71^{* *}$ & $0.55^{* *}$ & $0.56^{*}$ & 0.49 \\
\hline & b & & & & & & & & $0.65^{* *}$ & $0.67^{* *}$ & $0.73^{* *}$ & $0.85^{* *}$ \\
\hline \multirow{2}{*}{ BG } & $\mathrm{a}$ & & & & & & & & & 0.43 & $0.68^{* *}$ & $0.64^{*}$ \\
\hline & $\mathrm{b}$ & & & & & & & & & $0.75^{* *}$ & $0.69^{* *}$ & $0.86^{* *}$ \\
\hline \multirow{2}{*}{ GP } & $\mathrm{a}$ & & & & & & & & & & -0.33 & $0.74^{* *}$ \\
\hline & $\mathrm{b}$ & & & & & & & & & & $0.58^{* *}$ & $0.80^{* *}$ \\
\hline \multirow{2}{*}{ HI } & $\mathrm{a}$ & & & & & & & & & & & -0.35 \\
\hline & $\mathrm{b}$ & & & & & & & & & & & $0.79^{* *}$ \\
\hline
\end{tabular}

DF: days to flowering; DM: days to maturity; BP: number of branches/plant; PP: number of pod/plant; STMLC: stomatal conductance; LWP: leaf water potential; HSW: 100-seed weight; BG: biomass aboveground; GP: number of grain/pod; YP: yield/plant; HI: harvest index. ${ }^{* * *}$ Significant at $5 \%$ and $1 \%$ probability levels, respectively. a indicates watered conditions; $b$ indicates stressed conditions.

were obtained on yield per plant with stomatal conductance and leaf water potential $(r=0.73$ and $r=0.68)$, respectively. Under both conditions, 100-seed weight(HSW) showed a negative and nonsignificant correlation with days to maturity and flowering but was significant and positively correlated with all the traits across the treatments. The biomass aboveground and the number of grains per pod were found to be highly significant and positively $(p \leq 0.01)$ correlated (BG $(r=0.86)$ and GP $(r=0.79))$ with yield per plant under both treatments, whereas they were noticed to have a nonsignificant positive BG $(r=-0.32)$ and GP $(r=-0.17)$ relationship with the number of branches per plant under well-watered conditions. Significant and positive phenotypic correlations were obtained between stomatal conductance and leaf water potential under stressed conditions $(r=0.78)$. There was a significant and positive association between the number of grains per plant observed with BP $(r=0.77)$, PP $(r=0.69)$, HSW $(r=0.67)$, and BG $(r=0.75)$ under stressed treatments while the relationship with days to maturity $(r=-0.28)$ and days to flowering $(r=-0.41)$ was nonsignificant and negative under the watered condition. Correlation of days to maturity was positive and low with DF $(r=0.43)$, PP $(r=0.44)$, and BG $(r=0.38)$; however, relationship with BP was observed to be negative and low $(r=-0.30)$ under stressed conditions. Association of biomass aboveground under the stressed environment was significantly positive with BP $(r=0.65)$ and HSW $(r=0.65)$, whereas a nonsignificant and negative associated with DF $(r=-0.15)$. Number of pods per plant under watered condition showed a negatively nonsignificant correlation with $\mathrm{BP}(r=-0.40)$,
HSW $(r=-0.36)$, and BG $(r=-0.34)$ while positive and highly significant relationship with YP $(r=0.86)$ under similar conditions.

\section{Discussion}

Significant differences were observed within the common bean population for all the traits suggesting the presence of high level of genetic diversity among them. The relatively large population mean squares obtained for the number of pods per plant, harvest index, stomatal conductance, leaf water potential, and yield per plant under stressed conditions revealed that the progeny lines differed in their potential for these traits. Significant amount of phenotypic variability obtained indicated that all the progeny lines varied with each other. This implies that further improvement of the traits is likely through individual selection of plants. According to Beebe et al. [12], diverse source of tolerance to water stress in different common bean genotypes has been identified. This confirms that the single trait selection concept is not the most reliable way to improve a trait. According to this study, it was observed that selection for grain yield improvement under drought stress conditions should be conducted by simultaneous selection for many traits such as stomatal conductance, number of branches per plant, grain yield per plant, number of pods per plant, and harvest index. This can be attributed to the influence of the progeny lines by the interaction with the water treatment as shown by the results. The relatively higher CV\% for some of the traits might have been due to this higher variability of genotype $x$ 
treatment in the progeny line performance. This suggests that the evaluation of common bean population for drought tolerance traits under different levels of water stress rather than one level was quite satisfactory.

The close correspondence of the genotypic and the phenotypic variance for almost all traits indicated less influenced by environmental conditions, hence a wider scope for plant breeders to select common bean genotypes tolerant to drought. This agrees with Abebe et al. [13], Negash [14], and Ambachew et al. [15] whose findings showed that the contribution of the genetic effects outweighs the environmental effects for all traits in the estimation of phenotypic variance. In this study, the highest estimates for the genotypic and phenotypic coefficient of variation under water stress condition were recorded for the number of pods per plant and yield per plant, indicating that one of the most effective ways to increase grain yield under drought stress is to increase the number of pods. Wondwosen and Abebe [16] reported the negative association between grain yield and days to flowering under well-watered conditions demonstrating the importance of early flowering of a crop under water stress environments. These authors also reported that selection for earliness enhances the probability to escape drought and also improve the partitioning of the water absorbed and transpired after anthesis consequently affecting the grain yield. Asfaw et al. [4] also reported that under well-watered conditions, the grain yield and the number of branches exhibited a negative and nonsignificant correlation. However, in the present study, the two traits showed a positively strong and significant correlation under water deficit indicating that under stress condition, the grain yield was mainly influenced by the growth vigor of the plant and the amount of carbohydrate reserve available for remobilization. This positive correlation suggests that any improvement in the number of branches could result in a substantial increase in grain yield. These findings are consistent with those of Beebe et al. [12] who reported the presence of strong and positive correlations of grain yield with plant vigor under drought conditions. Darkwa et al. [17] demonstrated an evidence of a strong possibility of using accumulated biomass as a tool to improve grain yield. In agreement with this finding, high heritability and high genetic advance estimates were recorded for the two traits (Table 2). Ambachew et al. [15] established a negative and low correlation between branches per plant and yield per plant and contradicts our findings for the two traits. Such negative relationships with the grain yield indicate that basing selection on the two traits may not bring the desired improvement in grain yield. The utilization of genotypic and phenotypic correlations in the selection had previously been reported by several researchers [18-20]. The genotypic correlation coefficient provides the magnitude of the genetic association between traits and may offer an important selection criterion in plant breeding programs [21].

These results lead to the conclusion that traits which had a high amount of genetic variability, estimates of broad-sense heritability, genetic advance, and a high degree of positive and significant correlation coefficient under stress conditions would be very effective tools to be used in selection of high yielding common bean genotype under drought stress. Such traits in this study were number of pods, days to maturity, and yield per plant.

\section{Data Availability}

The numerical data used to support the findings of this study are included within the article.

\section{Conflicts of Interest}

The authors declare that there are no conflicts of interest regarding the publication of this paper.

\section{Acknowledgments}

The authors appreciate the technical and financial assistance given by the Agricultural and Mechanization Research Institute, Katumani, Kenya in support of this research.

\section{References}

[1] C. S. Wortmann and D. J. Allen, "African bean production and environments: their definition, characteristics and constraints," in CIAT Network on Bean Research in Africa, Occasional Publication Series No. 11, Dar es Salaam, Tanzania, 1994.

[2] B. M. Atta, M. A. Haq, and T. M. Shah, "Variation and interrelationships of quantitative traits in chickpea (Cicer aurantium L.)," Pakistan Journal of Botany, vol. 40, no. 2, pp. 637-647, 2008.

[3] S. Shukla, A. Bhargava, A. Chatterjee, A. Srivastava, and S. P. Singh, "Genotypic variability in vegetable amaranth (Amaranthus tricolor L.) for foliage yield and its contributing traits over successive cuttings and years," Euphytica, vol. 151, no. 1, pp. 103-110, 2006.

[4] A. Asfaw, D. Ambachew, T. Shah, and M. W. Blair, "Trait associations in diversity panels of the two common bean (Phaseolus vulgaris L.) gene pools grown under well-watered and water-stress conditions," Frontiers in Plant Science, vol. 8, p. 733, 2017.

[5] R. C. Alvares, F. C. Silva, L. C. Melo, P. G. S. Melo, and H. S. Pereira, "Estimation of genetic parameters and selection of high-yielding, upright common bean lines with slow seedcoat darkening," Genetics and Molecular Research, vol. 15, no. 4, article 15049081, 2016.

[6] E. B. Kouam, M. Ndomou, I. Gouad, and R. S. Pasquet, "Assessment of the genetic diversity of cultivated common beans (Phaseolus vulgaris L.) from Cameroon and Kenya using allozymes markers," Journal of Experimental Biology and Agricultural Sciences, vol. 5, no. 1, pp. 87-97, 2017.

[7] R. B. D. Steel and J. H. Torrie, Principles and Procedures of Statistics. A Biometrical Approach, McGrawHill Book Co., New York, NY, USA, 2nd edition, 1980.

[8] H. F. Robinson, R. E. Comstock, and P. H. Harvey, "Estimates of heritability and the degree of dominance in Corn1," Agronomy Journal, vol. 41, no. 8, pp. 353-359, 1949.

[9] G. W. Burton and E. H. Devane, "Estimating heritability in tall fescue (Festuca Arundinacea) from replicated clonal Material1," Agronomy Journal, vol. 45, no. 10, pp. 478-481, 1953.

[10] C. H. Hanson, H. F. Robinson, and R. E. Comstock, "Biometrical studies of yield in segregation populations of Korean Lespedeza1," Agronomy Journal, vol. 48, no. 6, pp. 268-272, 1956. 
[11] K. A. Gomez and A. A. Gomez, Statistical Procedures for Agricultural Research, John Wiley and Sons, New York, NY, USA, 2nd edition, 1984.

[12] S. E. Beebe, I. M. Rao, M. W. Blair, and J. A. Acosta-Gallegos, "Phenotyping common beans for adaptation to drought," Frontiers in Physiology, vol. 4, p. 35, 2013.

[13] A. Abebe, M. A. Brick, and R. A. Kirkby, "Comparison of selection indices to identify productive dry bean lines under diverse environmental conditions," Field Crops Research, vol. 58, no. 1, pp. 15-23, 1998.

[14] K. Negash, "Studies on genetic divergence in common bean (Phaseolus vulgaris L.) introductions of Ethiopia," M.Sc. thesis, Addis Ababa University, Addis Ababa, Ethiopia, 2006.

[15] D. Ambachew, F. Mekbib, A. Asfaw, S. E. Beebe, and M. W. Blair, "Trait associations in common bean genotypes grown under drought stress and field infestation by BSM bean fly," The Crop Journal, vol. 3, no. 4, pp. 305-316, 2015.

[16] W. Wondwosen and B. Abebe, "Genetic variability, heritability and genetic advance of some haricot bean (Phaseolus vulgaris $\mathrm{L}$.) varieties at bench-maji zone, southwest Ethiopia," Asian Journal of Crop Science, vol. 9, no. 4, pp. 133-140, 2017.

[17] K. Darkwa, D. Ambachew, H. Mohammed, A. Asfaw, and M. W. Blair, "Evaluation of common bean (Phaseolus vulgaris L.) genotypes for drought stress adaptation in Ethiopia," The Crop Journal, vol. 4, no. 5, pp. 367-376, 2016.

[18] E. J. van Oosteron and E. Acevedo, "Adaptation of barley (Hordeum vulgare L.) to harsh Mediterranean environments," Euphytica, vol. 62, no. 1, pp. 1-14, 1992.

[19] G. Marroig and J. M. Cheverud, "A comparison of phenotypic variation and covariation patterns and the role of phylogeny, ecology, and ontogeny during cranial evolution of new world monkeys," Evolution, vol. 55, no. 12, pp. 2576-2600, 2001.

[20] J. K. Conner, I. A. Cooper, R. J. La Rosa, S. G. Pérez, and A. M. Royer, "Patterns of phenotypic correlations among morphological traits across plants and animals," Philosophical Transactions of the Royal Society B: Biological Sciences, vol. 369, no. 1649, article 20130246, 2014.

[21] R. T. Resende, M. D. V. Resende, F. F. Silva et al., "Regional heritability mapping and genome-wide association identify loci for complex growth, wood and disease resistance traits in Eucalyptus," New Phytologist, vol. 213, no. 3, pp. 1287-1300, 2017. 


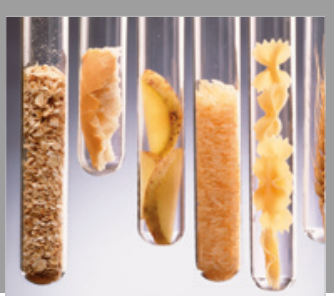

International Journal of Food Science

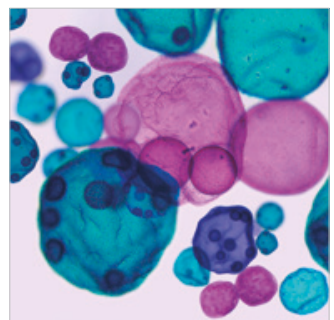

International Journal of Microbiology
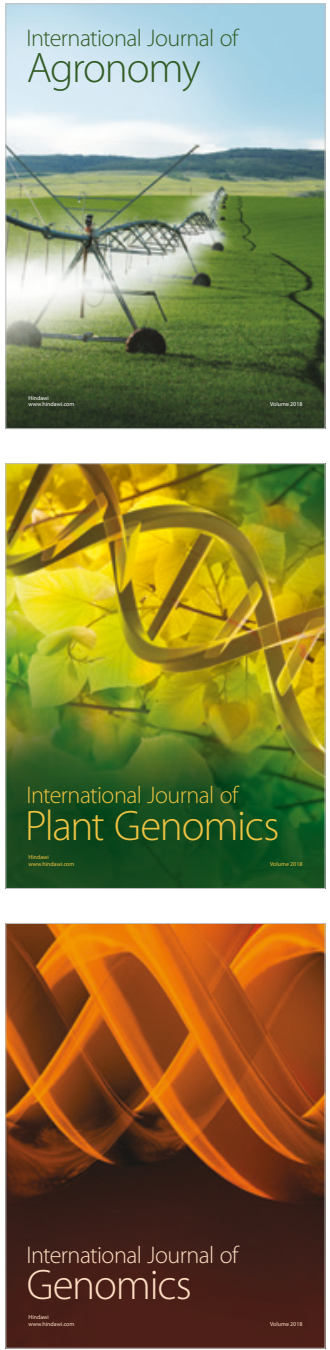

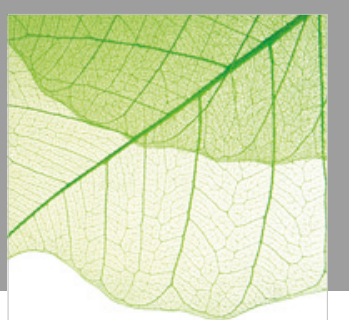

Journal of Botany
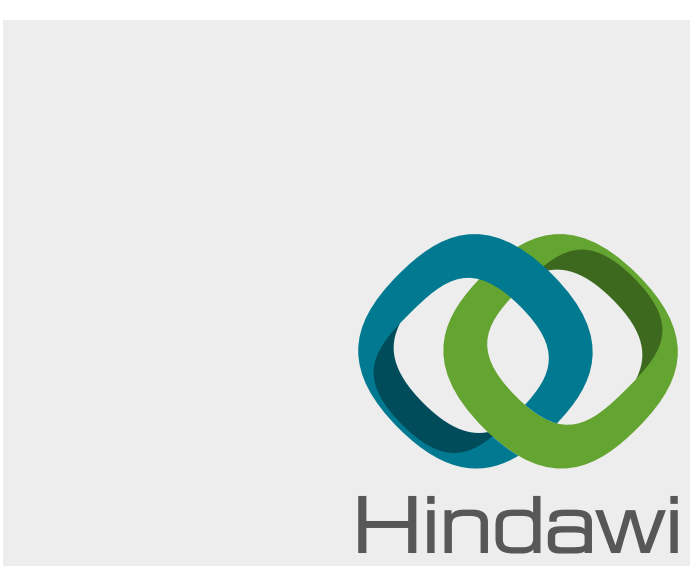

Submit your manuscripts at

www.hindawi.com
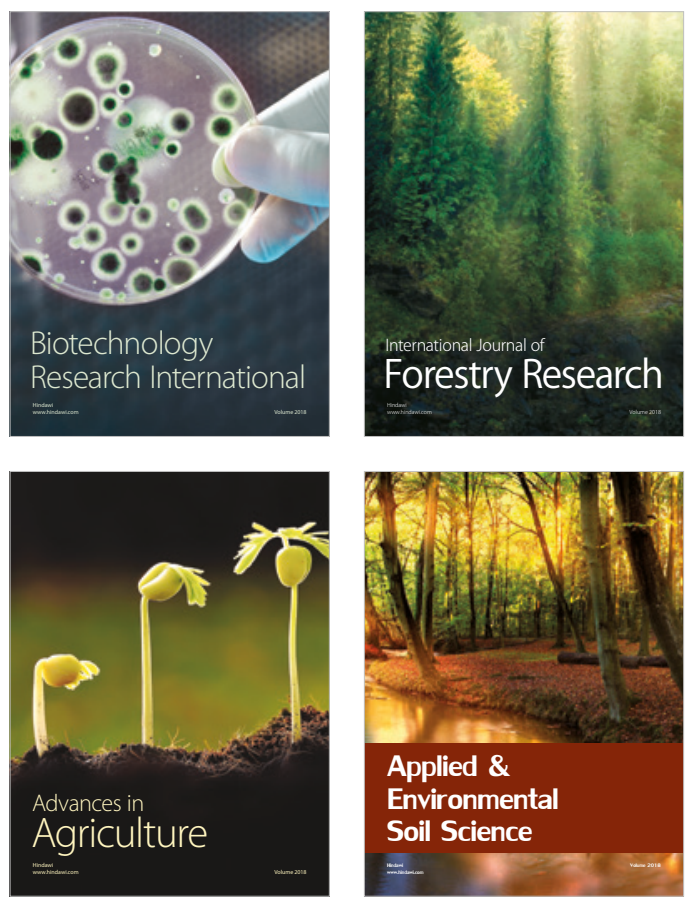

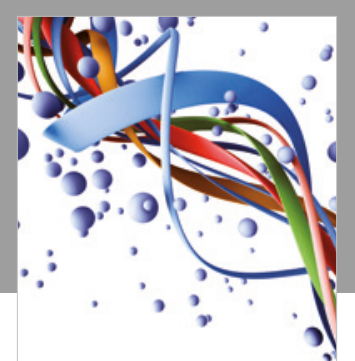

Scientifica

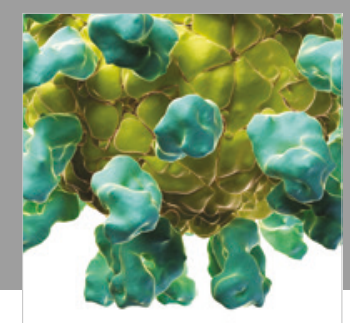

Veterinary Medicine International

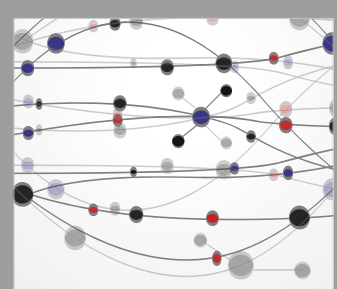

The Scientific World Journal
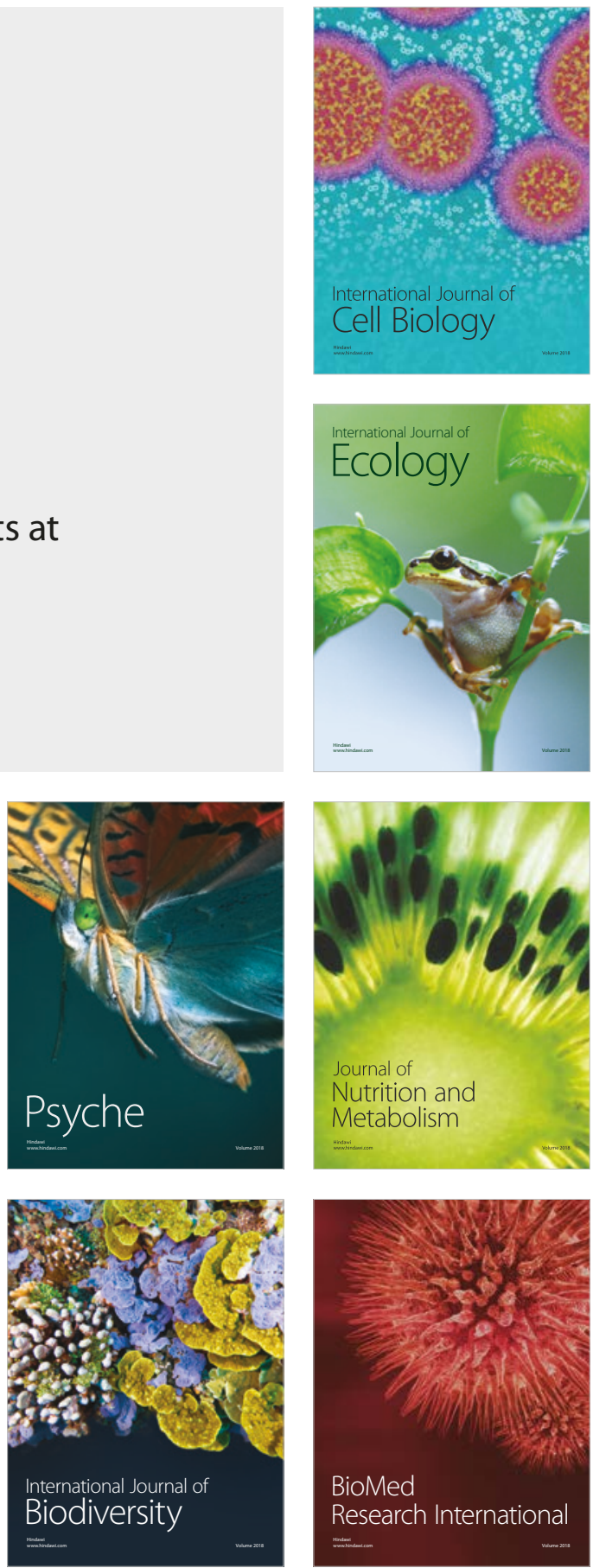